\title{
Leinaweaver, Jessaca. (2009). Los niños ayacuchanos: Una antropología de la adopción y la construcción familiar en el Perú. Lima: Instituto de Estudios Peruanos.
}

En este trabajo, Jessaca Leinaweaver (2009) analiza cómo los niños de zonas rurales son trasladados a vivir a nuevos hogares de las zonas urbanas. Para esto, toma como punto de partida el fenómeno de la circulación infantil, al cual denomina «ubicación en la casa de parientes, en instituciones públicas y en familias adoptivas» (Leinaweaver, 2009, p. 17). Es decir, la circulación infantil refiere a la práctica de reubicar a un hijo o a una hija en un nuevo hogar. Esta práctica de parentesco fue tomada de otras investigaciones antropológicas que abordan el tema (Fonseca, 1986, p. 15). El interés Leinaweaver (2009) es analizar las implicancias sociales que median detrás del proceso de adopción de niños en la ciudad de Huamanga (Ayacucho). Este estudio es una fuerte evidencia crítica con la cual la autora evalúa el sistema de adopción en el Perú, el cual se centra en referencias occidentales y se aleja de la concepción andina de la adopción.

La obra está estructurada en dos grandes apartados. Dentro de la descripción y análisis del libro, la autora toma como referencias las historias recogidas durante sus dos años de trabajo de campo en Ayacucho. La primera parte de la obra engloba la circulación infantil en el contexto de diferentes historias de madres, padres y niños, desde una historia del conflicto étnico y de violencia, hasta una historia de corte internacional sobre los derechos de los niños, la adopción y los huérfanos. Una de las historias principales revela la situación de una familia que se vale de la circulación infantil para lograr mayor apoyo laboral, situación en la cual las familias remitentes enfrentan las presiones económicas que implica la crianza de los hijos. Esto quiere decir que, en palabras de la autora, la circulación se ve motivada por intereses económicos de familias que buscan un crecimiento o mejoría en términos de movilidad social. Esta circulación permite la realización de metas familiares y media entre grupos sociales diferentes, creando muchos y valiosos vínculos.

Asimismo, la autora introduce la idea de «huérfano» wakcha, un término quechua clave para entender las distintas nociones de la circulación infantil. La autora explica que, según lo recopilado por Betanzos (1996), wakcha es una palabra quechua que reúne principalmente dos ideas: una referida a una persona pobre y otra referida a una persona abandonada (huérfana). Su análisis se centra en la explicación de que este término quechua concibe la orfandad en términos 
de abandono por incapacidad de asumir responsabilidades paternas a causa de distintos factores (p. e. la pobreza, la irresponsabilidad). En otras palabras, este término no concibe la orfandad a causa de la muerte de los progenitores, sino del abandono parental y comunal. Esta es una de las ideas centrales que fundamenta la crítica dirigida hacia las instituciones del Estado, las cuales conciben principalmente la orfandad a partir de la muerte de los padres, noción tomada de la cultura occidental (Leinaweaver, 2009, p. 108). Esto revela que la visión estatal desnaturaliza la crianza de los comuneros indígenas, ya que descuida (y condena) la posibilidad de adopción de parientes cercanos a la familia (lo que se concreta con la circulación infantil).

En un siguiente punto, la autora hace una revisión a la historia de Ayacucho. Se concentra en explicar la creación de orfanatos a partir de la aparición del grupo terrorista Sendero Luminoso. Se hace hincapié en los contextos antes y después del Conflicto Armado Interno en el Perú. Sobre esto, se menciona que, antes de la guerra, Ayacucho era una ciudad sin presencia de huérfanos, ya que no había situaciones de muertes y matanzas y que, en casos en los cuales se encontraban con padres difuntos, los parientes o la comunidad se encargaba de criar a los huérfanos. Sin embargo, durante la aparición de Sendero Luminoso, la ciudad de Ayacucho se enfrentó a matanzas masivas de padres. Esto generó que se apareciera (o se hiciera consciente) la presencia de niños huérfanos. Ante esta situación, en los años 80 y 9o, iniciaron a abrir sus puertas los primeros orfanatos, los cuales se concentraban a reunir a los niños huérfanos víctimas de la violencia terrorista. La adopción de los niños ayacuchanos se realizó con mayor frecuencia de padres interesados desde EE. uU. y de Europa. Frente a todo lo dicho, la autora explica la adopción relacionándola con los hechos de violencia surgidos y, como efecto, la pobreza que atravesó la ciudad. Esto se vio reflejado en sus entrevistas de los agentes sociales (como asistencias sociales, agentes de adopciones), quienes concuerdan en que la pobreza y la violencia fueron las raíces de la orfandad y de la creación de puericultorios.

La segunda mitad del libro está compuesta por los capítulos 4, 5 y 6. En estos capítulos, se presenta la etnografía específica, descripciones detalladas y las interpretaciones de las historias de vida. Para esto, la autora regresa a la noción de la circulación infantil, la cual es entendida como un proceso activo que conduce a la formación y transformación de vínculos. Leinaweaver (2009) explica la práctica de parentesco «compadrazgo», la cual refiere al "parentesco ficticio en el que dos familias se vinculan a través de un compromiso» (Leinaweaver, 2009, p.

\section{Lengua y Sociedad}


23). Una de las ventajas de esta práctica es que se crean fuertes alianzas entre las familias (compadres): se establece una fuerte relación bidireccional de compadres. La noción del compadrazgo es una idea clave para entender la circulación infantil, ya que, a partir de la relación de compadres, se establecen fuertes lazos y alianzas que permiten establecer qué parientes serán los padres meta de los niños. Generalmente, la figura del compadre, bajo la línea de la autora, es una persona relacionada con la vida urbana, a quien se la relaciona con un poder económico elevado (o diferenciado de la pobreza). Este es un punto importante que permite explicar las motivaciones que suscitan la práctica de la circulación infantil, porque esta persigue como uno de sus fines la movilidad social.

Bajo la idea de la movilidad social, se debe entender que, para una niña, su propia circulación puede ser para superar «salir adelante», lo que les permite un ascenso social a los niños, porque pueden transitar entre posiciones económicas para lograr mejoras educativas. Para ilustrar, se presenta el caso de una niña bajo el pseudónimo de Reyna. El caso de Reyna representa a una menor que fue a vivir con la comadre de su padre, Cristina, una viuda de setenta años. Carlos, el padre de Reyna, envía a Reyna a la casa de su comadre para que pueda estudiar y acompañar a la pariente anciana. La reubicación de Reyna desde la casa de sus padres hasta la casa de Cristina representa tanto un acto de solidaridad hacia alguien que es percibido como un pariente. Este ejemplo demuestra que otra de las motivaciones de la circulación infantil es la compañía. Los niños que son enviados buscan evitar la soledad de los parientes. Así, acompañar implica compartir el espacio social y físico con un pariente. El acompañamiento o compañía es una característica de la relación interdependiente padre-hijo, lo que es una pieza clave en la circulación infantil. En acompañamiento, también, se asemeja a una convivencia activa, como un trabajo infantil, debido a que la gran mayoría de niños reubicados termina realizando labores domésticas. La familiarización es un esfuerzo activo y comprometido para convertirse en familia, un proceso que alude a la condición delicada y de construcción del parentesco. Así, se van reforzando los lazos y la construcción de la familia para los niños.

De modo semejante, la autora, también, explica que pasar por una circulación infantil también engloba ideas de superación de los menores. Ayacucho es una ciudad caracterizada por altos índices de pobreza; ante esto, lo que se busca es la superación ayacuchana. La idea de superación ayacuchana, en palabras de la autora, supone vestirse con ropa de occidental, hablar más castellano que quechua, educarse, comer fideos en vez de papas, vivir en la ciudad en lugar de vivir en 
el campo. En otras palabras, la superación se reconstruye con ideas que buscan alejarse de los marcadores indígenas. Entonces, se puede decir que el progreso social de los andinos ayacuchanos implica alejarse de su cultura tradicional y asemejarse a la cultura occidental, un rasgo que evidencia autodiscriminación.

En líneas generales, el punto general de este libro es que la circulación infantil es una alternativa de mejora social ante situaciones de pobreza, en las cuales las familias ayacuchanos deciden circular a sus hijos hacia familias mejores posicionadas económicamente con la finalidad de buscar un ascenso social para ellos, además de brindar compañía a los parientes que se encuentran solitarios. La circulación infantil atraviesa por procesos como acostumbrarse y desacostumbrarse de hábitos que permiten que los niños puedan adaptarse a sus nuevas condiciones de vida en sus nuevas familias. Durante este proceso, se van reforzando los lazos familiares que los unirán con sus padres adoptantes. Como es evidente, con este aporte de Leinaweaver (2009), los estudios sobre la circulación infantil se ven enriquecidos y repensados hacia una nueva ruta que considera la visión andina del Perú, visión que ha estado descuidada por el Estado (Ludeña González, 200o, p. 76). La idea central de esta crítica está dirigida hacia un Estado que condena la circulación infantil y que no toma en cuenta como proceso de adopción formal, sobre todo porque toma la concepción occidental de orfandad (padres difuntos). En ese sentido, su libro es un aporte en la literatura de parentesco porque describe el sentido de lo que es convertirse en pariente a lo largo del tiempo, lo que involucra avivar y reforzar lazos familiares y, a su vez, debilitarlos.

Pamela Jimenez Lizama

\section{Bibliografía}

Betanzos, J. D. de. (1996). Narrative of the Incas. Austin: University of Texas.

Fonseca, C. (1986). Orphanages, foundlings, and Foster mothers: The system of child circulation in a Brazilian squatter settlement. En Anthropological Quarterly, 59(1), 15-27.

Leinaweaver, J. (2009). Los niños ayacuchanos: Una antropología de la adopción y la construcción familiar en el Perú. Lima: Instituto de Estudios Peruanos.

Ludeña González, G. (2000). Un debido proceso de adopción para nuestros niños $y$ adolescentes. Lima: G\&S.

180 Lengua y Sociedad 